Article

\title{
Investigation of Wettability, Drying and Water Condensation on Polyimide (Kapton) Films Treated by Atmospheric Pressure Air Dielectric Barrier Discharge
}

\author{
Natalia Khomiakova, Jan Hanuš, Anna Kuzminova and Ondřej Kylián *(i) \\ Department of Macromolecular Physics, Faculty of Mathematics and Physics, Charles University, \\ V Holešovickách 2, 18000 Praha 8, Czech Republic; natasha12394@mail.ru (N.K.); jan.hanus@gmail.com (J.H.); \\ annakuzminova84@gmail.com (A.K.) \\ * Correspondence: ondrej.kylian@gmail.com; Tel.: +420-95155-2258
}

Received: 4 June 2020; Accepted: 28 June 2020; Published: 29 June 2020

check for updates

\begin{abstract}
In this study, we report on the investigation of influence of air atmospheric pressure dielectric barrier discharge on polyimide (Kapton) films. It is shown that plasma treatment causes a significant increase of Kapton wettability that is connected with alterations of its chemical composition (oxidation) induced by dielectric barrier discharge. Observed variations in the wettability of Kapton were also found to be accompanied by changes in the dynamics of water droplets drying on plasma-treated Kapton, namely by the reduction of the constant contact angle phase of the droplet drying. This effect may be ascribed to the higher surface heterogeneity of plasma-treated Kapton that causes pinning of the edges of drying droplet on the Kapton surface. Finally, the differences in wettability induced by the plasma treatment led to a different way, how the water condensates on the Kapton surface: while the condensing water forms large amount of small droplets on untreated Kapton, much bigger water structures were found on the Kapton exposed to atmospheric plasma.
\end{abstract}

Keywords: Kapton; dielectric barrier discharge; surface modification

\section{Introduction}

Kapton, which is a polyimide material developed by the Du Pont company in the 1960s is one of the high-performance polymers that exhibits remarkable properties (high heat resistance with upper working temperature in the range $250-320^{\circ} \mathrm{C}$, good mechanical properties with tensile strength of $230 \mathrm{MPa}$, good dielectric properties with dielectric constant 3.4 and low-outgassing in a vacuum). This makes Kapton a highly valuable and popular material in a wide range of modern technologies that include, for instance, flexible electronics, optoelectronics and spintronic (e.g., electronic skin applications, flexible sensors, or solar cells [1-7]) or aircraft and aerospace industries [8,9]. However, despite its advantageous bulk properties, the possible use of Kapton is limited by its rather low wettability, inertness and low adhesion. Because of this, various strategies were developed with an aim to reduce inherent surface hydrophobicity, insufficient adhesion and/or inertness of Kapton to comply with demands in various applications that are based on the utilization of protection/adhesion layers, chemical treatment, ion beams or ultra-violet radiation [10-16]. As an analogy to other polymers, an interesting alternative to the aforementioned approaches represents plasma-based techniques. The popularity of these methods is connected with the fact that they are capable, under appropriate conditions, to modify surfaces of a treated object without the alteration of its bulk characteristics. The modification of polymers may proceed by two principal ways: (i) coating of an object with a material with the required surface properties (e.g., $[17,18]$ ), or (ii) by the use of non-depositing plasma that alters 
the surface chemical composition and/or morphology of treated material. The latter approach was already tested on a wide range of polymers using both low-pressure [19-21] and atmospheric pressure plasma [22-26] generated in different gases or gas mixtures. From the practical point of view, special attention is nowadays devoted to the dielectric barrier discharges (DBD) operated at atmospheric pressure in air that allow for the fast and cost-effective treatment of polymers. For instance, it was demonstrated in our previous studies that several seconds of DBD plasma treatment may promote covalent immobilization of biomolecules on otherwise bio-inert polytetrafluoroethylene (PTFE) [27] or enhance adhesion, growth and proliferation of certain cell types on polyethylene terephthalate (PET) [28].

Concerning the plasma treatment of polyimide films, the main attention has been devoted to the possibility to promote the adhesion between the plasma-treated polyimide surface and subsequently deposited metallic coating (e.g., copper [29-34]). Based on the reported results, it has been found that plasma treatment is indeed capable of inducing a substantial increase of surface energy of Kapton that in turn enhances the adhesive strengths of metallic films onto polyimide substrates. However, the majority of early works employed low-pressure plasma treatment that is in many cases not compatible with the demand of a cheap and fast process [29-31]. Because of this, further studies were performed with atmospheric pressure plasmas generated in different gases and gas mixtures such as $\mathrm{He} / \mathrm{O}_{2} / \mathrm{NF}_{3}$ [32], $\operatorname{Ar}$ [33], $\mathrm{N}_{2}$ /air [34]. It has been reported that the activation and hydrophilization of polyimide films may be achieved also in these cases in a relatively short period of time that ranged, depending on the operational condition, from several seconds up to several minutes. However, similarly to the treatment and processing of other polymers (e.g., [35-38]), the cost of the treatment that is connected in the case of atmospheric pressure plasma mainly with the gas consumption may be further decreased when laboratory air is used as the working gas.

The main aim of this study is to investigate in detail the suitability of DBD plasma treatment for the enhancement of the wettability of Kapton. In contrast to the previous reports, this study includes also the evaluation of the impact of the plasma treatment of Kapton on the dynamics of water droplet drying or water condensation on its surface, as well as presents the strategy that allows for the fabrication of Kapton surfaces patterned by areas with low and high wettability.

\section{Materials and Methods}

DBD plasma reactor, previously employed for the modification of PET, Nylon and PTFE foils $[27,28,39]$, was used in this study. A schematic diagram of this DBD system is depicted in Figure 1. The plasma was generated between two parallel planar electrodes. The top electrode (dimensions $20 \mathrm{~mm} \times 20 \mathrm{~mm} \times 50 \mathrm{~mm}$ ) was made of stainless steel and was moveable along the length of the bottom electrode. The bottom electrode (dimensions $72 \mathrm{~mm} \times 160 \mathrm{~mm}$ ) was a grounded steel plate covered with 1-mm-thick sintered alumina. The distance between the top and bottom electrodes was $2.0 \mathrm{~mm}$. The upper electrode was powered by a high-voltage $(\sim 20 \mathrm{kV})$, low-frequency $(\sim 20 \mathrm{kHz})$ alternating current power supply. The power was $30 \mathrm{~W}$ and the plasma was ignited in laboratory air. As reported in our previous studies this led to the formation of filamentary plasma (see Figure 1) with an average $\sim 10^{6}$ microdischarges per second [40]. 


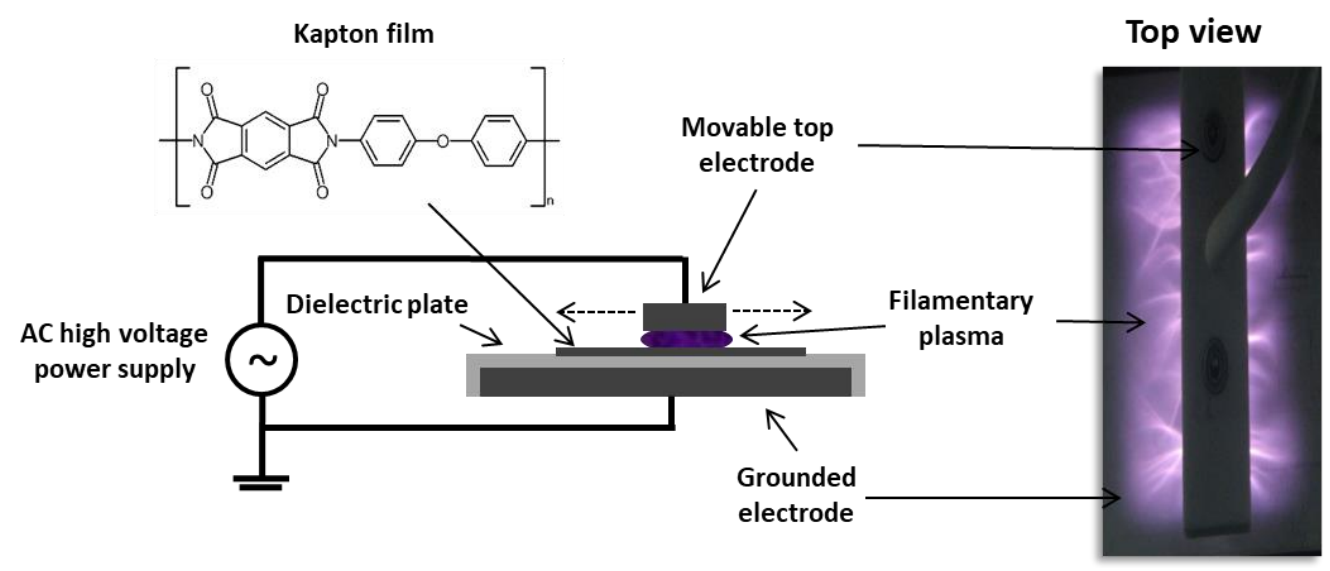

Figure 1. Schematic of the dielectric barrier discharge (DBD) system used for the treatment of Kapton and photography of DBD plasma.

The samples to be treated, commercially available Kapton $\mathrm{HN}^{\circledR}$ films (thickness of $0.125 \mathrm{~mm}$, Goodfellow Cambridge Limited, Huntingdon, UK, used as received, chemical structure presented in Figure 1), were cut into the strips (commonly $2.5 \mathrm{~cm} \times 4.0 \mathrm{~cm}$ ) and placed onto the bottom electrode. Such prepared samples were subsequently exposed to the DBD plasma. To treat the whole surface of the Kapton strips, the top electrode was scanned over the samples (up to 40 times) with the constant scanning speed $40 \mathrm{~mm} / \mathrm{s}$. The highest number of scans corresponded to the $20 \mathrm{~s}$ exposure of the entire surface of the Kapton sample to the plasma.

Wettability and surface energy of the Kapton films before the plasma treatment, immediately after plasma treatment and after different storage times (on air at room temperature) was measured by a goniometer of own construction. It consisted of a syringe with testing liquid (ultrapure water and diiodomethane, both sourced from Sigma Aldrich, St. Louis, MO, USA), substrate holder and camera connected to a computer. The droplets were gently put onto the samples and photographed immediately after their deposition as well as during their evaporation. Acquired images were subsequently manually processed and contact angle and contact radius, i.e., the radius of the droplet in contact with the Kapton film, were determined. The surface energy was calculated from the contact angles of water and diiodomethane using the Fowkes theory [41]. In addition to this, the evaporation of the water droplets was also studied by gravimetry. In this case water droplets (volume of $4 \mu \mathrm{L}$ ) were spotted onto the Kapton samples positioned on Mettler Toledo XS205 balances (Mettler Toledo, Columbus, OH, USA). The weight of the drying droplets was recorded with a time step of $15 \mathrm{~s}$. All the experiments were performed in the laboratory air at room temperature $22-25^{\circ} \mathrm{C}$ and relative humidity in the range from $35-40 \%$.

The chemical structure of Kapton films was determined by X-ray photoelectron spectroscopy (XPS) that was carried out using an XPS spectrometer equipped with a hemispherical analyzer (Phoibos 100, Spec, Berlin, Germany) and using Al K $\alpha$ X-rays source (1486.6 eV, 12 kV, 200 W, Specs, Berlin, Germany). The elemental composition was determined from the XPS survey spectra that were recorded with step $0.5 \mathrm{eV}$ at pass energy of $40 \mathrm{eV}$. High-resolution XPS spectra of $\mathrm{C} 1 \mathrm{~s}, \mathrm{O}$ 1s and $\mathrm{N} 1 \mathrm{~s}$ regions were measured with the step of $0.05 \mathrm{eV}$ and pass energy $15 \mathrm{eV}$. Each of high-resolution XPS spectra was measured 10 times to obtain a sufficient spectral resolution and to lower the noise level. Acquired XPS spectra were charge referenced to the $\mathrm{C} 1 \mathrm{~s}$ peak of $284.7 \mathrm{eV}$, which corresponds to the carbon in an aromatic ring [42]. The fitting of high-resolution XPS spectra of $C 1$ s and $O$ 1s peaks was performed using the CasaXPS program after the Shirley background subtraction.

Morphology of the Kapton films was assessed by atomic force microscopy (AFM, Quesant Q-scope 350 ) in the semi-contact mode (scan rate $2 \mathrm{~s}$ ) using ACLA-10 Si probes (tip radius $<10 \mathrm{~nm}$, AppNano, Mountain View, CA, USA). The scanned area was $10 \mu \mathrm{m} \times 10 \mu \mathrm{m}$. The acquired AFM images were analyzed by open-source Gwyddion software. 
Finally, the etching rate of Kapton by DBD plasma was estimated by gravimetry. In these experiments, the strips of Kapton film were weighed before and after the plasma treatment using Mettler Toledo XS205 balances (Mettler Toledo, Columbus, OH, USA).

\section{Results and Discussion}

\subsection{Morphology and Surface Chemical Composition}

The first studied parameter was the surface chemical composition of Kapton before and after the DBD plasma treatment. For untreated Kapton the surface elemental concentration calculated from the integral intensities of the peaks present in the survey XPS spectra was found to be close to the theoretical values for Kapton-the carbon concentration was 78\% (theoretical value 75.9\%), nitrogen concentration was $6 \%$ (theoretical value $6.9 \%$ ) and surface concentration of oxygen was $16 \%$ (theoretical value $17.2 \%$ ). As it is presented in Table 1, already $1 \mathrm{~s}$ of the plasma treatment led to the increase of the oxygen concentration up to approximately $22 \%$ that was accompanied by the decrease of the carbon surface concentration that dropped down to $71 \%$. Because of this, the $\mathrm{O} / \mathrm{C}$ ratio was found to increase by $50 \%$ from 0.2 measured on untreated Kapton up to 0.32 on Kapton exposed to the DBD plasma for $1 \mathrm{~s}$. The prolongation of the treatment had no further impact on the surface chemical composition that remained approximately the same for all treatment times.

Table 1. The elemental composition of untreated and DBD-treated Kapton as measured by X-ray photoelectron spectroscopy (XPS).

\begin{tabular}{ccccc}
\hline Treatment Time (s) & C (at.\%) & O (at.\%) & N (at.\%) & O/C \\
\hline 0 & 78 & 16 & 6 & 0.21 \\
1 & 71 & 22.5 & 6.5 & 0.32 \\
10 & 71 & 21.5 & 7.5 & 0.30 \\
20 & 71 & 22 & 7 & 0.31 \\
\hline
\end{tabular}

In order to get a better insight to the changes into the surface chemical composition of Kapton as induced by the DBD treatment, the high-resolution spectra of $C 1$ s and $O 1$ s peaks were analyzed using the same approach as in the previous study [15] and the $C$ 1s peak was fitted by 5 components. The peak at the binding energy of $284.7 \mathrm{eV}$ (denoted as $\mathrm{C} 1$ in Figure 2) was attributed to the carbon atoms in the aromatic ring of the oxydianiline (ODA) part of Kapton; the peak at $285.5 \mathrm{eV}$ (C2 in Figure 2) belongs to the carbons in the benzene ring in the pyromellitic dianhydride (PMDA) structure of the Kapton as well as to $\mathrm{C}-\mathrm{N}$ bonds, the peaks at $286.3 \mathrm{eV}$ (C3) and $288.6 \mathrm{eV}$ (C4) correspond to single $\mathrm{C}-\mathrm{O}$ bonds and carbonyl $\mathrm{C}=\mathrm{O}$ bonds, respectively. In addition, a weak peak with the highest binding energy was attributed to the satellite peak that is connected with $\pi \rightarrow \pi^{*}$ transition. Here again, a relatively good match for untreated Kapton with the theoretical structure was observed. The most pronounced deviation from the theoretical values was observed for $\mathrm{C}=\mathrm{O}$ bonds ( $13 \%$ measured, $18 \%$ theoretical value), which is, however, a common situation that is due to the cross-linking or hydrogen bonding $[15,43]$. The $\mathrm{C}=\mathrm{O}$ bond deficiency in comparison with the ideal stoichiometric concentration was observed also when $\mathrm{O} 1 \mathrm{~s}$ peak was analyzed. In this case, two components were used to fit $\mathrm{O} 1$ s peak-the component at $532 \mathrm{eV}$ (denoted as $\mathrm{O} 1$ in Figure 2) belongs to $\mathrm{C}=\mathrm{O}$ carbonyl bonds, while the peak at the higher binding energy ( $\mathrm{O} 2$ in Figure 2) corresponds to $\mathrm{C}-\mathrm{O}-\mathrm{C}$ bonds. The measured ratio of these two components is 7:3, while the theoretical value ratio is $4: 1$. 

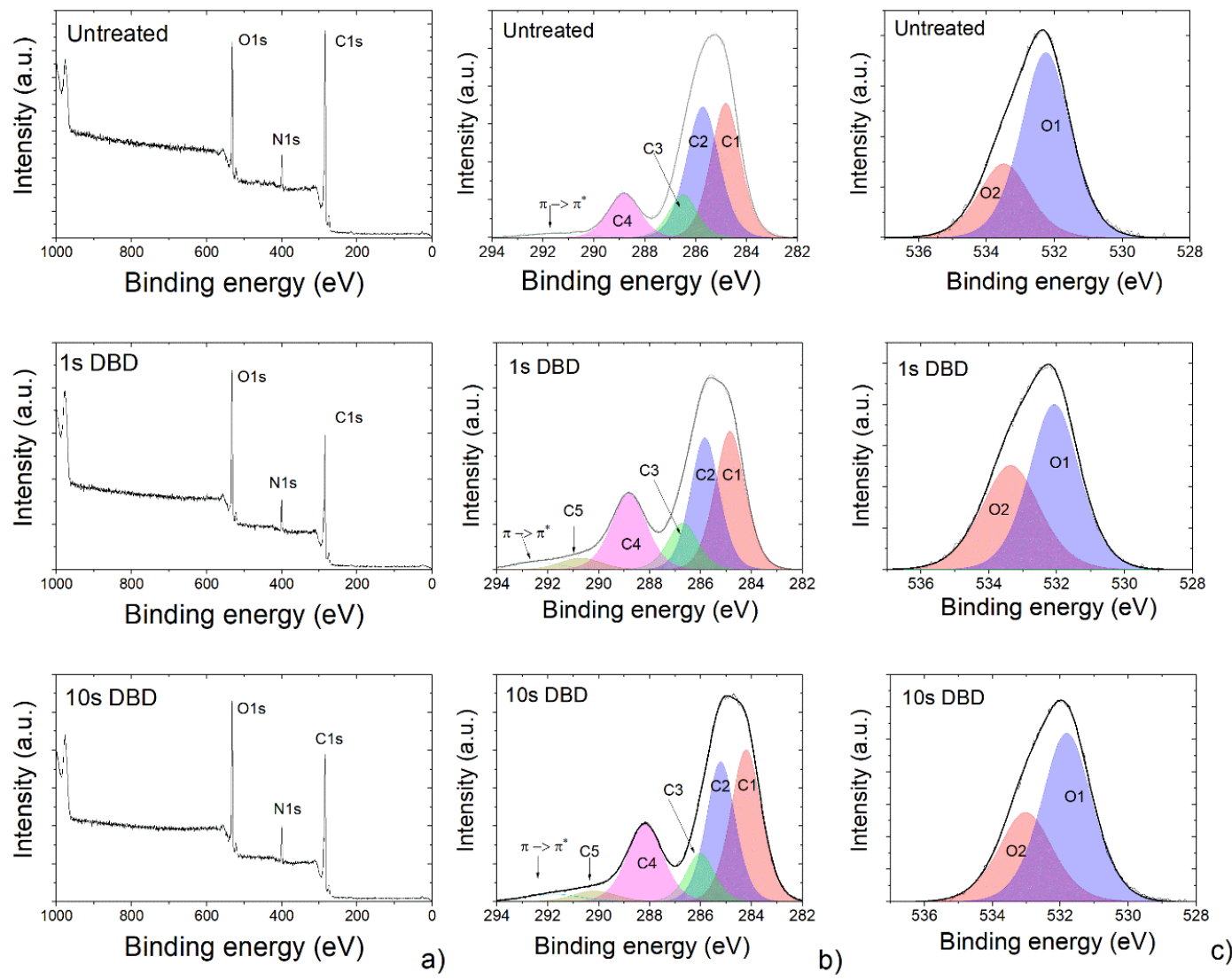

Figure 2. (a) Survey XPS spectra and high-resolution XPS spectra of (b) C 1s peak and (c) O 1s peak. Panels show XPS of untreated Kapton (top), XPS spectra after $1 \mathrm{~s}$ of DBD treatment (middle) and XPS spectra after $10 \mathrm{~s}$ of DBD treatment (bottom).

In the case of DBD-treated Kapton, considerable changes were observed in both C 1s and O 1s XPS peaks. First of all, it was not possible to fit the $C 1$ s peak by 5 components as in the case of untreated samples: an additional peak at $290.7 \mathrm{eV}$ (denoted C5 in Figure 2) had to be added that corresponds to carbonates. Alongside with the appearance of this spectral peak, the intensity of the peak at the binding energy of $288.6 \mathrm{eV}$ increased by approximately $50 \%$ from about $13 \%$ up to $21 \%$ that was accompanied by the decrease of the $\mathrm{C} 1$ and $\mathrm{C} 2$ peaks, which contains either $\mathrm{C}-\mathrm{N}$ bonds or carbons in the PMDA and ODA structure. The increased abundance of oxygen-containing bonds and formation of new carbonate bonds clearly shows effective oxidation of Kapton surface, which is in good agreement with previously reported studies focused on the air DBD treatment of polymers $[24,26,28]$. This, in turn, causes also the changes in the $\mathrm{O} 1 \mathrm{~s}$ XPS spectra that show a relative increase of $\mathrm{C}-\mathrm{O}$ bonds previously reported also for PET [28] or Nylon [39].

Concerning the AFM measurements, the DBD plasma was found to have a strong impact on the surface morphology of Kapton film. While the untreated Kapton was smooth with the value of root-mean-square (RMS) roughness $1.0 \mathrm{~nm}$, the atmospheric pressure air DBD treatment led to the formation of surface nanostructures randomly distributed on the Kapton surface. As it is depicted in Figure 3, different populations of nanostructures that differ in dimensions (both lateral and vertical ones) may be recognized on Kapton film in dependence on the treatment time: besides small "bumps" that were visible already after $1 \mathrm{~s}$ of the DBD treatment, much bigger nanostructures become observable for longer treatment times. This effect may also be clearly demonstrated on the height histograms presented in Figure $3 \mathrm{~b}$ that become highly asymmetric with distinguishable peaks at different heights for longer treatment durations. Such behavior may be caused either by the reorganization of the Kapton surface exposed to the plasma or by gradual and spatially inhomogeneous removal of the material from the surface of Kapton. In order to shed the light onto this phenomenon, the removal rate 
was measured by gravimetry. This experiment confirmed relatively fast etching of Kapton with the removal rate close to $0.6 \mu \mathrm{g} / \mathrm{s} \mathrm{cm}^{2}$, which is a value close to the previously published etching rates for other polymers using the same DBD reactor and similar operational conditions [40]. Taking into account the density of Kapton $\left(1.42 \mathrm{~g} \mathrm{~cm}^{-3}\right.$ according to the material data sheet) this value corresponds to the etching rate of $4 \mathrm{~nm} / \mathrm{s}$. This means that $10 \mathrm{~s}$ of plasma treatment should induce the removal of approximately $40 \mathrm{~nm}$ of the Kapton top-layer. In the case of spatially homogeneous etching, the Kapton surface should remain smooth and only its thickness should decrease. In the second limiting case, in which only some fraction of Kapton is removed by the plasma and the rest stays intact, the heights of formed nanostructures should be at least $40 \mathrm{~nm}$ after $10 \mathrm{~s}$ of plasma treatment duration. As this is not the situation observed by AFM that indicated the maximal height of nanostructures after $10 \mathrm{~s}$ of plasma treatment to be only $25 \mathrm{~nm}$, it can be concluded that the entire surface of the Kapton sample is etched, but at different rates.
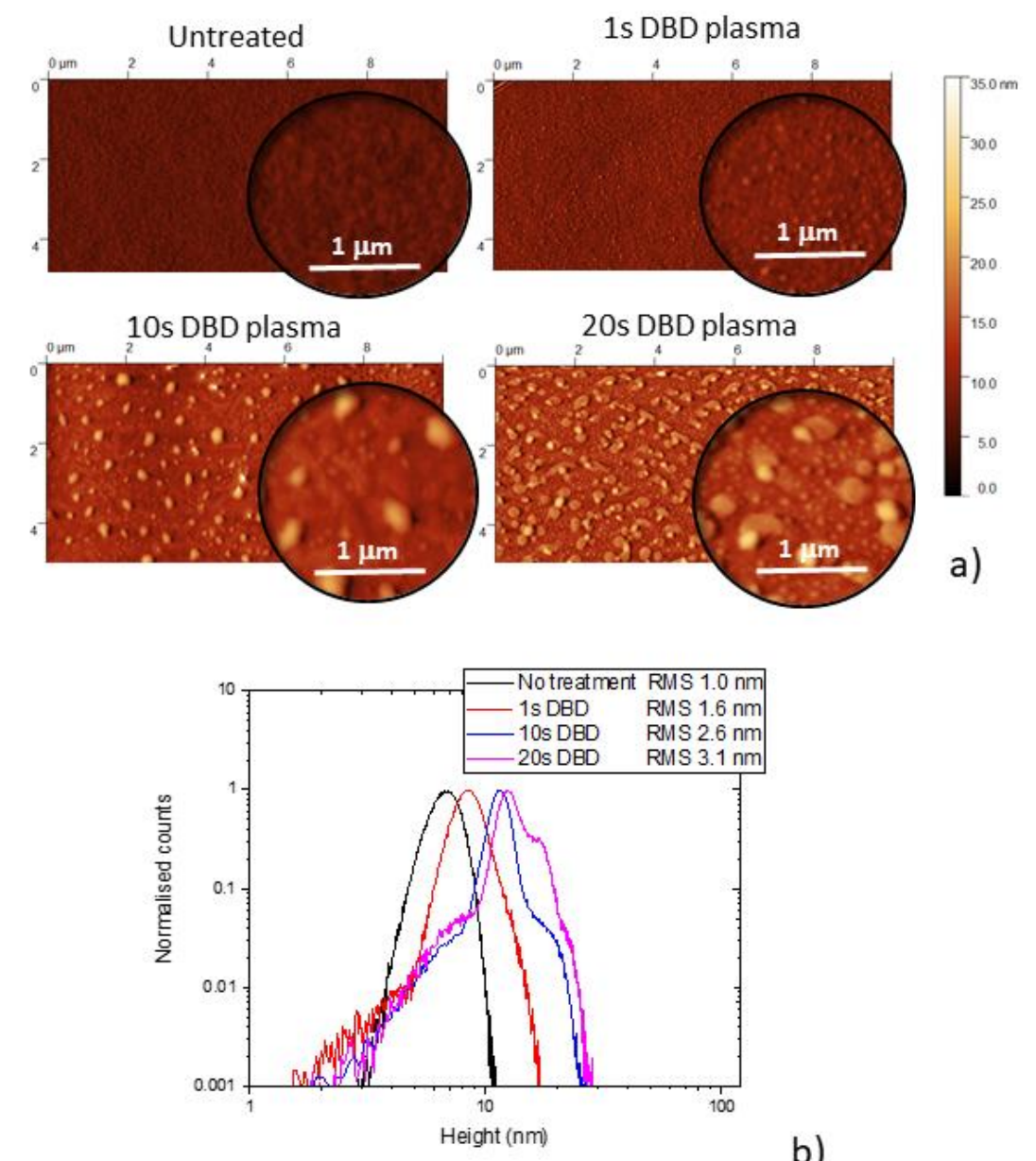

b)

Figure 3. (a) Atomic force microscopy (AFM) images of untreated and DBD-treated Kapton and (b) corresponding height histograms.

\subsection{Wettability}

The changes in the surface chemical composition and morphology induced by the DBD treatment described in the previous section have a strong impact on the wetting on the Kapton surface. First of all, the plasma treatment was found to induce a dramatic decrease in the static water contact angle. As can be seen in Figure 4, the static contact angle dropped from about 80 degrees measured on untreated Kapton film down to 24 degrees already after $1 \mathrm{~s}$ of plasma treatment that is a value comparable with results reported previously for polyimide treated by the nanosecond-pulse DBD in atmospheric air [44]. This rapid decrease was then followed by a slight decrease in water contact angle with a further 
increase of the plasma treatment duration. In a similar way behaved also dynamic contact angles, i.e., advancing and receding contact angles. The aforementioned changes in the surface wettability of Kapton exposed to the DBD plasma are connected with the significant rise of the surface free energy that was found to increase from $52 \mathrm{~mJ} / \mathrm{m}^{2}$ measured for untreated Kapton up to $75 \mathrm{~mJ} / \mathrm{m}^{2}$ for Kapton treated for $1 \mathrm{~s}$. Such a change in surface energy is predominantly given by the increase of its polar part (from $4 \mathrm{~mJ} / \mathrm{m}^{2}$ up to $36 \mathrm{~mJ} / \mathrm{m}^{2}$ ) that is connected with the formation of polar oxygen-containing groups on the surface of DBD-treated Kapton that were observed by XPS. Furthermore, as the XPS did not indicate any changes in the surface chemical composition of Kapton film for all treatment times, the slight increase of Kapton wettability for longer treatment times should be ascribed to the gradual increase of its roughness as observed by AFM.
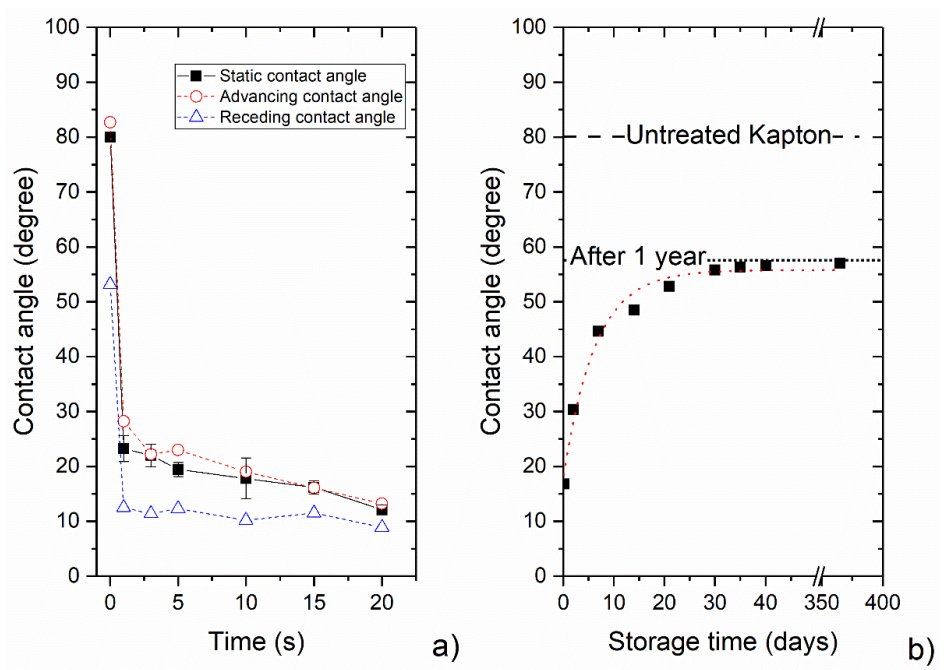

Figure 4. (a) Static and dynamic water contact angles in dependence on the duration of the DBD treatment of Kapton and (b) evolution of the water contact angle with the storage time (treatment duration $10 \mathrm{~s})$.

Although a substantial increase of Kapton wettability after its DBD plasma treatment was observed, the high surface wettability was not found to be temporally stable and gradually decreased with the storage time (see Figure $4 \mathrm{~b}$ ). This effect, sometimes termed as hydrophobic recovery, is common for plasma-treated polymers and is connected either with the reorientation of polar functional groups on the surface of polymers, migration of fragments from the surface into the bulk or with the accumulation of carbon-containing air-born impurities [45-47]. To quantify the characteristic time-scale of this process, that defines the time-scale at which the plasma-induced hydrophilization of Kapton surface is persistent, the values of water contact angles measured at different storage times $\theta(t)$ were fitted by an empirical formula [48]:

$$
\theta(t)=\theta_{\text {sat }}-A \cdot e^{-\frac{t}{\tau}}
$$

where $\theta_{\text {sat }}$ stands for the saturation contact angle reached after the infinite storage time and $\tau$ represents the characteristic restoration time of the contact angle. According to the fitting procedure of measured data, the characteristic time $\tau$ was determined to be 6.2 days that is close to the previously reported value for DBD-treated polyether ether ketone (PEEK) [49]. However, it is important to note, that despite its increase, the water contact angle did not reach the value measured on untreated Kapton even after 1 year from the DBD treatment.

Another issue connected with the DBD treatment, which may be of interest for applications, is the possibility to fabricate surfaces with spatially distinguishable and well-defined wettability patterns, i.e., surfaces with zones that possess markedly different wettability. To demonstrate this option, the Kapton film was covered by a silicon gasket (1-mm-thick) with an array of circular openings ( $3 \mathrm{~mm}$ in diameter) and plasma treated for $10 \mathrm{~s}$ (see Figure 5). The role of the gasket was to shield certain parts of Kapton 
from the plasma that thus modified only the part of Kapton not covered by the gasket. After the DBD treatment, the gasket was gently removed and the Kapton was immersed into distilled water for $5 \mathrm{~s}$ and then gently withdrawn. Due to the differences in wettability of plasma-treated and untreated parts the water preferentially accumulated on the zones that were exposed to the plasma and formed a well-defined array of droplets that copies the geometry of the gasket (Figure 5).

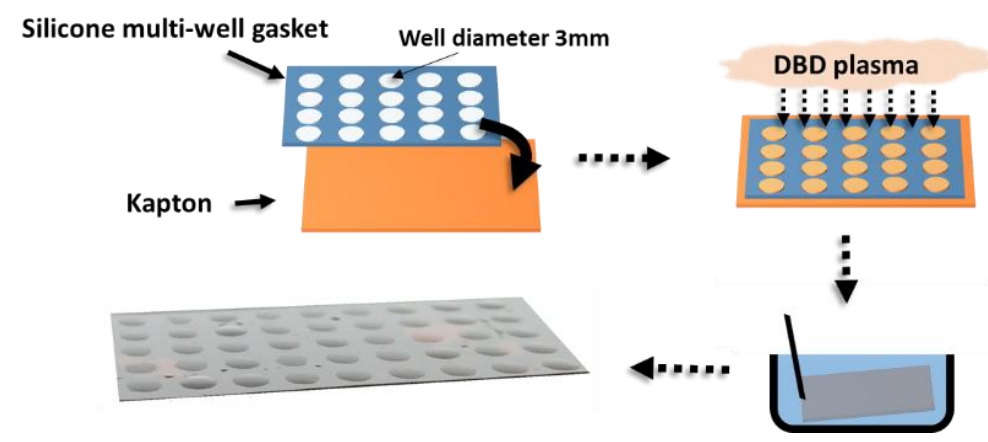

Figure 5. Schematic representation of the step used for the fabrication of Kapton surface with wettability patterns using a silicon multi-well gasket and DBD plasma and photography of resulting array of water droplets.

\subsection{Droplet Drying and Condensation}

Another phenomenon connected with the DBD treatment of Kapton is changing the way, how a water droplet dries on its surface. In the case of untreated Kapton, the drying followed three easily distinguishable drying modes (Figure 6). In the first one, the drying droplet gradually changed its contact angle, but its contact radius stayed constant. This, so-called constant contact radius (CCR) drying mode [50], changed as soon as the contact angle of the droplet reached value around 50 degrees. In this case, further droplet evaporation led to the decrease of the contact radius, while the contact angle stayed almost unchanged (so-called constant contact angle (CCA) mode [50]). The angle, at which the CCR to CCA transition occurred defines the receding contact angle. Finally, both contact angle and contact radius decreased with increasing evaporation time (so-called mixed mode) at the terminal stages of the droplet drying. In contrast to the untreated sample, for all samples exposed to DBD plasma the CCA drying phase was absent, which means that the triple line of the droplet stayed pinned on the surface for almost all of the time as the drop evaporates. In agreement with the results reported in the previous study, in which PEEK foils were treated by the DBD plasma [49], the absence of the CCA drying mode was persistent even for prolonged storage times for which the water contact angle increased up to $60^{\circ}$. Such pinning may be ascribed to the increased inhomogeneity of surface morphology caused by the plasma that was witnessed by AFM (Figure 3).

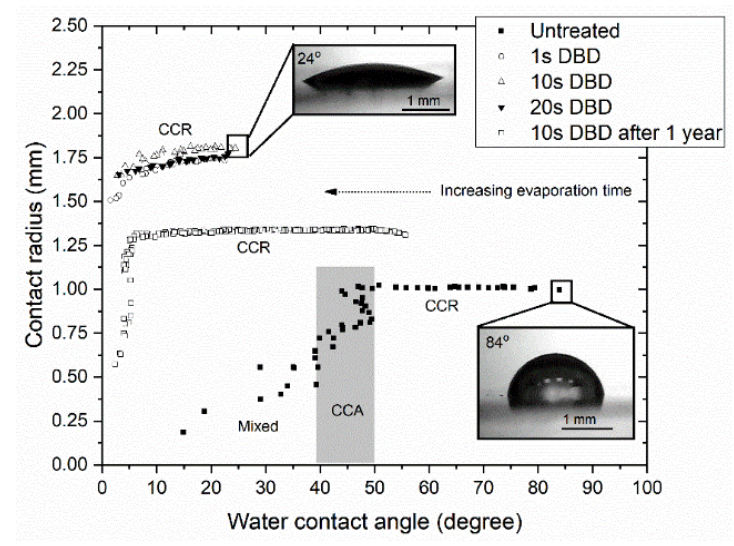

Figure 6. Dynamics of the water droplet drying expressed as the dependence of the contact radius on the water contact angle. 
Different drying dynamics on untreated and DBD-treated Kapton may be demonstrated also by the gravimetry when the evaporation was monitored by measurement of the droplet mass during its evaporation. Two important findings were observed as it is demonstrated in Figure 7 for droplets having the same initial volume/mass. The first phenomenon is much faster evaporation of the droplet on plasma-treated Kapton. This effect is connected with an approximately 2 times bigger surface area of the droplet on the Kapton previously exposed to the DBD plasma that is due to its higher wettability and with it connected spreading of water of Kapton surface. The second effect presented in Figure 7 is the different temporal behavior of the evaporation rate. In the case of plasma-treated Kapton, the dependence of the mass change of the drying droplet was found to be almost linear. In fact, the measured data were fitted by the power law [51]:

$$
\left(\frac{m}{m_{o}}\right)^{\beta}=\left(1-\frac{t}{t_{f}}\right)
$$

where $m$ is the mass of the droplet, $m_{0}$ is the initial mass of the droplet, $\beta$ is the scaling exponent that depends on the drying mode, $t$ is the evaporation time and $t_{f}$ is the time needed for the complete droplet evaporation. As can be seen in Figure 7, the scaling exponent $\beta$ is close to 1 which confirms the linearity of the mass change of the droplet with the evaporation time. According to the numerical studies this scaling exponent is typical for the drying of droplets in the CCR mode [52,53]. This situation is markedly different from the one observed for untreated Kapton. Although in this case, the initial decrease of the droplet mass may be fitted with power law using exponent $\beta$ close to 1 , the measured data start to deviate from the linear trend after $10 \mathrm{~min}$ of evaporation. At this time point, the mass decrease corresponds to the scaling exponent $\beta$ equal to 0.65 . Such value suggests the change of the drying mode and corresponds to the theoretically predicted and experimentally confirmed exponent $2 / 3$ for sessile droplet drying in CCA mode $[50,54,55]$. This drying mode terminates at the evaporation time close to 18 min when the drying changes to mixed mode.

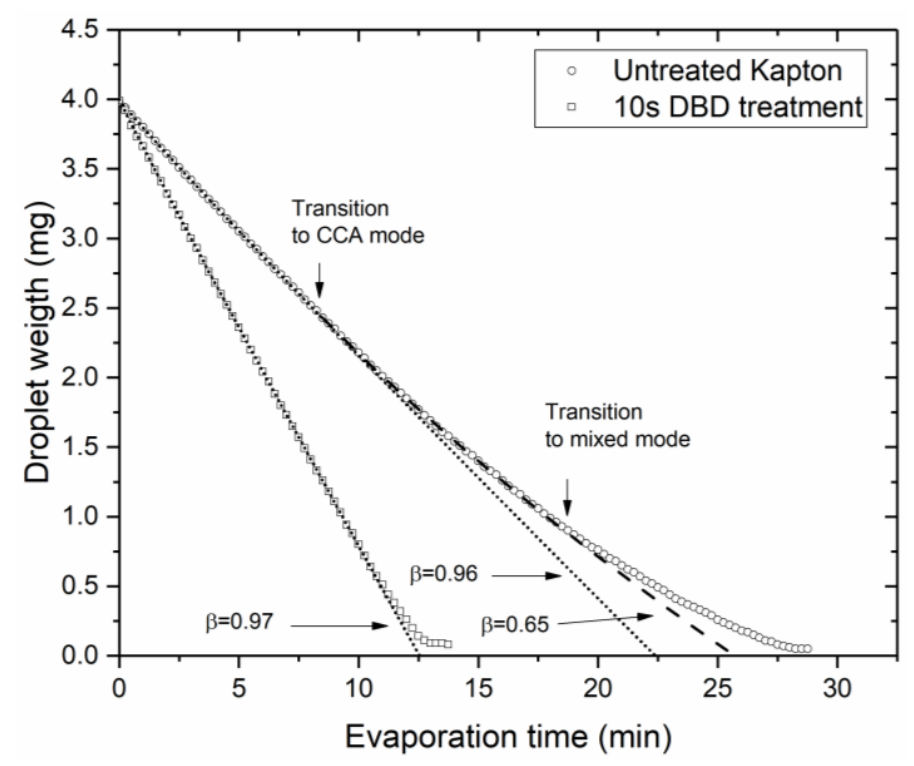

Figure 7. Mass of the droplet versus evaporation time.

Finally, the changes in wettability induced by the DBD plasma treatment affect the way, how water condensates on the Kapton surface, which is often overlooked in the literature devoted to the plasma-treatment of polymers. To demonstrate this, one half of the Kapton strip was exposed to the DBD, while its second part was shielded by a silicon solid gasket. Such a prepared sample was then exposed to the steam generated by boiling water (see Figure 8). Markedly different condensation was observed: while the untreated part of the Kapton retained its visual appearance after water 
condensation, the part that was DBD treated were readily covered by a water film. This difference was due to the different levels of hydrophilicity of treated/untreated parts on the sample. On the more hydrophobic, i.e., plasma untreated, part of the Kapton, water formed upon condensation small randomly distributed individual droplets as it was confirmed by optical microscope. In contrast, the water tends to form considerably bigger water structures on the plasma-treated and thus also more hydrophilic part of Kapton. According to the theoretical models, such structures originate from the rupture of the film-like water condensate formed at the early stages of the water condensation on hydrophilic surfaces [56].

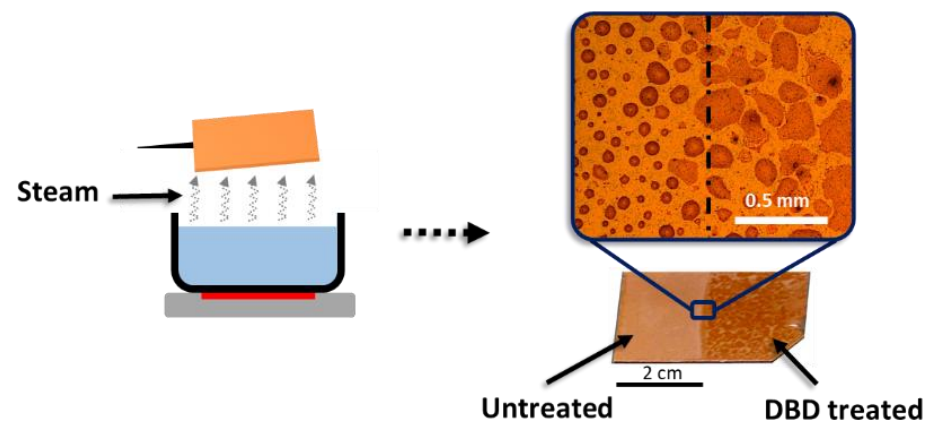

Figure 8. Condensation of water on plasma-treated and untreated Kapton.

\section{Conclusions}

To conclude, the effect of DBD atmospheric pressure air plasma treatment of the Kapton surface was studied with respect to the wetting, drying and water droplet condensation. It was demonstrated that DBD treatment causes the formation of nanostructures on the surface of Kapton as well as leads to its rapid oxidation as witnessed by XPS. These changes in turn influence the wettability that was found to rapidly decrease from $80^{\circ}$ down to approximately $20^{\circ}$. As shown, this effect may be utilized for the facile production of well-defined wettability patterns when a mask is introduced in between plasma and Kapton. Furthermore, the plasma treatment also influenced the dynamics of water droplet drying, namely it caused an absence of constant contact angle drying phase. Unlike the water contact angle of a sessile droplet that tends to increase with increasing the storage time with characteristics time 6.2 days, the alteration of the droplet's drying dynamics was found to be persistent. This effect may be ascribed to the pinning of the triple line of the evaporating droplet by surface nanostructures created on the Kapton surface during its plasma treatment. Finally, the changes in the wettability of Kapton induced by the DBD plasma led to a different way, how the water condensates on its surface. It was found that the condensing water formed small droplets on untreated and more hydrophobic Kapton, whereas water structures with a much bigger size were found on the DBD-treated Kapton.

All of the aforementioned effects should be thus carefully considered when plasma treatment is used for the modification of Kapton as it may impact its required performance. Concerning this, our results show that when only the wettability or surface energy is important for a particular application, $1 \mathrm{~s}$ DBD treatment is sufficient. In contrast, in the situations when certain level of nanoroughness has also to be achieved, prolonged treatment times are necessary.

Author Contributions: Conceptualization, methodology, supervision, writing-review and editing, O.K.; writing-original draft preparation, N.K.; investigation, N.K., A.K., and J.H. All authors have read and agreed to the published version of the manuscript.

Funding: The work was supported by the project of the Charles University: SVV 260 579-2020.

Conflicts of Interest: The authors declare no conflicts of interest. 


\section{References}

1. Pecora, A.; Maiolo, L.; Cuscunà, M.; Simeone, D.; Minotti, A.; Mariucci, L.; Fortunato, G. Low-temperature polysilicon thin film transistors on polyimide substrates for electronics on plastic. Solid State Electron. 2008, 52, 348-352. [CrossRef]

2. Hosseindokht, Z.; Mohammadpour, R.; Asadian, E.; Paryavi, M.; Rafii-Tabar, H.; Sasanpour, P. Low cost flexible pressure sensor using laser scribed GO/RGO periodic structure for electronic skin applications. Superlattice. Microst. 2020, 140, 106470. [CrossRef]

3. Han, S.-T.; Peng, H.; Sun, Q.; Venkatesh, S.; Chung, K.-S.; Lau, S.C.; Zhou, Y.; Roy, V.A.L. An Overview of the Development of Flexible Sensors. Adv. Mater. 2017, 29, 1700375. [CrossRef]

4. $\quad$ Lindner, E.; Cosofret, V.V.; Ufer, S.; Buck, R.P.; Kusy, R.P.; Ash, R.B.; Nagle, H.T. Flexible (Kapton-based) microsensor arrays of high stability for cardiovascular applications. J. Chem. Soc. Faraday Trans. 1993, 89, 361-367. [CrossRef]

5. Bahramiabarghouei, H.; Porter, E.; Santorelli, A.; Gosselin, B.; Popović, M.; Rusch, L.A. Flexible 16 Antenna Array for Microwave Breast Cancer Detection. IEEE Trans. Biomed. Eng. 2015, 62, 2516-2525. [CrossRef]

6. Herrero, J.; Guillén, C. Transparent films on polymers for photovoltaic applications. Vacuum 2002, 67, 611-616. [CrossRef]

7. Bedoya-Pinto, A.; Donolato, M.; Gobbi, M.; Hueso, L.E.; Vavassori, P. Flexible spintronic devices on Kapton. Appl. Phys. Lett. 2014, 104, 062412.

8. Ennis, C.P.; Kaiser, R.I. Mechanistical studies on the electron-induced degradation of polymethylmethacrylate and Kapton. Phys. Chem. Chem. Phys. 2010, 12, 14902-14915. [CrossRef]

9. Rahnamoun, A.; Engelhart, S.P.; Humagain, S.; Koerner, H.; Plis, E.; Kennedy, W.J.; Cooper, R.; Greenbaum, S.G.; Hoffmann, R.; van Duin, A.C.T. Chemical dynamics characteristics of Kapton polyimide damaged by electron beam irradiation. Polymer 2019, 176, 135-145. [CrossRef]

10. Gouzman, I.; Girshevitz, O.; Grossman, E.; Eliaz, N.; Sukenik, C.N. Thin Film Oxide Barrier Layers: Protection of Kapton from Space Environment by Liquid Phase Deposition of Titanium Oxide. ACS Appl. Mater. Interfaces 2010, 2, 1835-1843. [CrossRef]

11. Gallais, L.; Bergeret, E.; Wang, B.; Guerin, M.; Bènevent, E. Ultrafast laser ablation of metal films on flexible substrates. Appl. Phys. A 2014, 115, 177-188. [CrossRef]

12. Ghosh, I.; Konar, J.; Bhowmick, A.K. Surface properties of chemically modified polyimide films. J. Adhes. Sci. Technol. 1997, 11, 877-893. [CrossRef]

13. Bachman, B.J.; Vasile, M.J. Ion bombardment of polyimide films. J. Vac. Sci. Technol. A 1989, 7, $2709-2716$. [CrossRef]

14. Shin, J.; Jeun, J.; Kang, P. Surface modification and characterization of $\mathrm{N}+$ ion implantation on polyimide film. Macromol. Res. 2010, 18, 227-232. [CrossRef]

15. Ektessabi, A.M.; Hakamata, S. XPS study of ion beam modifiedpolyimide films. Thin Solid Films 2000, 377-378, 621-625. [CrossRef]

16. Gotoh, K.; Nakata, Y.; Tagawa, M.; Tagawa, M. Wettability of ultraviolet excimer-exposed PE, PI and PTFE films determined by the contact angle measurements. Colloids Surf. A Physicochem. Eng. Asp. 2003, 224, 165-173. [CrossRef]

17. Kylián, O.; Drábik, M.; Polonskyi, O.; Čechvala, J.; Artemenko, A.; Gordeev, I.; Choukourov, A.; Matolínová, I.; Slavínská, D.; Biederman, H. Deposition of nanostructured fluorocarbon plasma polymer films by RF magnetron sputtering of polytetrafluoroethylene. Thin Solid Films 2011, 519, 6426-6431. [CrossRef]

18. Kylián, O.; Kuzminova, A.; Hanuš, J.; Slavínská, D.; Biederman, H. Super-hydrophilic SiOx coatings prepared by plasma enhanced chemical vapor deposition combined with gas aggregation source of nanoparticles. Mater. Lett. 2018, 227, 5-8. [CrossRef]

19. Tsougeni, K.; Vourdas, N.; Tserepi, A.; Gogolides, E.; Cardinaud, C. Mechanisms of oxygen plasma nanotexturing of organic polymer surfaces: From stable super hydrophilic to super hydrophobic surfaces. Langmuir 2009, 25, 11748-117459. [CrossRef]

20. Rymuszka, D.; Terpiłowski, K.; Borowski, P.; Holysz, L. Time-dependent changes of surface properties of polyether ether ketone caused by air plasma treatment. Polym. Int. 2016, 65, 827-834. [CrossRef] 
21. Vesel, A.; Primc, G.; Zaplotnik, R.; Mozetic, M. Applications of highly non-equilibrium low pressure oxygen plasma for treatment of polymers and polymer composites on an industrial scale. Plasma Phys. Control Fusion 2020, 62, 024008. [CrossRef]

22. Cui, N.-Y.; Brown, N.M.D. Modification of the surface properties of a polypropylene (PP) film using an air dielectric barrier discharge plasma. Appl. Surf. Sci. 2002, 189, 31-38. [CrossRef]

23. Esena, P.; Riccardi, C.; Zanini, S.; Tontini, M.; Poletti, G.; Orsini, F. Surface modification of PET film by a DBD device at atmospheric pressure. Surf. Coatings Technol. 2005, 200, 664-667. [CrossRef]

24. Borcia, G.; Anderson, C.A.; Brown, N.M.D. The surface oxidation of selected polymers using an atmospheric pressure air dielectric barrier discharge. Part I. Appl. Surf. Sci. 2004, 221, 203-214. [CrossRef]

25. Borcia, G.; Anderson, C.A.; Brown, N.M.D. The surface oxidation of selected polymers using an atmospheric pressure air dielectric barrier discharge. Part II. Appl. Surf. Sci. 2004, 225, 186-197. [CrossRef]

26. Homola, T.; Matoušek, J.; Hergelová, B.; Kormunda, M.; Wu, L.Y.L.; Černák, M. Activation of poly(methyl methacrylate) surfaces by atmospheric pressure plasma. Polym. Degrad. Stab. 2012, 97, 886-892. [CrossRef]

27. Bilek, M.M.M.; Vandrovcová, M.; Shelemin, A.; Kuzminova, A.; Kylián, O.; Biederman, H.; Bačáková, L.; Weiss, A.S. Plasma treatment in air at atmospheric pressure that enables reagent-free covalent immobilization of biomolecules on polytetrafluoroethylene (PTFE). Appl. Surf. Sci. 2020, 518, 146128. [CrossRef]

28. Kuzminova, A.; Vandrovcová, M.; Shelemin, A.; Kylián, O.; Choukourov, A.; Hanuš, J.; Bačáková, L.; Slavínská, D.; Biederman, H. Treatment of poly (ethylene terephthalate) foils by atmospheric pressure air dielectric barrier discharge and its influence on cell growth. Appl. Surf. Sci. 2015, 357, 689-695. [CrossRef]

29. Inagaki, H.; Tasaka, S.; Hibi, K. Improved adhesion between plasma-treated polyimide film and evaporated copper. J. Adhes. Sci. Technol. 1994, 8, 395-410. [CrossRef]

30. Usami, K.; Ishijima, T.; Toyoda, H. Rapid plasma treatment of polyimide for improved adhesive and durable copper film deposition. Thin Solid Films 2012, 521, 22-26. [CrossRef]

31. Lin, Y.-S.; Liu, H.-M.; Chen, C.-L. Plasma surface modification of polyimide films by air glow discharge for copper metallization on microelectronic flex substrates. Surf. Coat. Technol. 2006, 200, 3775-3785. [CrossRef]

32. Lee, S.B.; Kim, Y.-K. Adhesion Improvement of Polyimide/Metal Interface by $\mathrm{He} / \mathrm{O}_{2} / \mathrm{NF}_{3}$ Atmospheric Pressure Plasma. Plasma Process. Polym. 2009, 6, S525-S529. [CrossRef]

33. Peng, S.; Li, L.; Li, W.; Wang, C.; Guo, Y.; Shi, J.; Zhang, J. Surface Modification of Polyimide Film by Dielectric Barrier Discharge at Atmospheric Pressure. Plasma Sci. Technol. 2016, 18, 337-341. [CrossRef]

34. Park, W.J.; Yoon, S.G.; Jung, W.S.; Yoon, D.H. Effect of dielectric barrier discharge on surface modification characteristics of polyimide film. Surf. Coat. Technol. 2007, 201, 5017-5020. [CrossRef]

35. Kostov, K.G.; dos Santos, A.L.R.; Honda, R.Y.; Nascente, P.A.P.; Kayama, M.E.; Algatti, M.A.; Mota, R.P. Treatment of PET and PU polymers by atmospheric pressure plasma generated in dielectric barrier discharge in air. Surf. Coat. Technol. 2010, 204, 3064-3068. [CrossRef]

36. Ren, C.-S.; Wang, K.; Nie, Q.-Y.; Wang, D.-Z.; Guo, S.-H. Surface modification of PE film by DBD plasma in air. Appl. Surf. Sci. 2008, 255, 3421-3425. [CrossRef]

37. Kormunda, M.; Homola, T.; Matousek, J.; Kovacik, D.; Cernak, M.; Pavlik, J. Surface analysis of poly(ethylene naphthalate) (PEN) films treated at atmospheric pressure using diffuse coplanar surface barrier discharge in air and in nitrogen. Polym. Degrad. Stab. 2012, 97, 547-553. [CrossRef]

38. Upadhyay, D.J.; Cui, N.-Y.; Anderson, C.A.; Brown, N.M.D. A comparative study of the surface activation of polyamides using an air dielectric barrier discharge. Colloid. Surf. A 2004, 248, 47-56. [CrossRef]

39. Kuzminova, A.; Shelemin, A.; Kylián, O.; Choukourov, A.; Valentová, H.; Krakovský, I.; Nedbal, J.; Slavínská, D.; Biederman, H. Study of the effect of atmospheric pressure air dielectric barrier discharge on nylon 6, 6 foils. Polym. Degrad. Stab. 2014, 110, 378-388. [CrossRef]

40. Kuzminova, A.; Kretková, T.; Kylián, O.; Hanuš, J.; Khalakhan, I.; Prukner, V.; Doležalová, E.; Šimek, M.; Biederman, H. Etching of polymers, proteins and bacterial spores by atmospheric pressure DBD plasma in air. J. Phys. D Appl. Phys. 2017, 50, 135201. [CrossRef]

41. Fowkes, F.M. Attractive forces at interfaces. Ind. Eng. Chem. 1964, 56, 40-52. [CrossRef]

42. Beamson, G.; Briggs, D. High Resolution XPS of Organic Polymers; John Wiley \& Sons: Chichester, UK, 1992.

43. Flitsch, R.; Shih, D.-Y. An XPS study of argon ion beam and oxygen RIE modified BPDA-PDA polyimide as related to adhesion. J. Adhes. Sci. Technol. 1996, 10, 1241-1253. [CrossRef]

44. Shao, T.; Zhang, C.; Long, K.; Zhang, D.; Wang, J.; Yan, P.; Zhou, Y. Surface modification of polyimide films using unipolar nanosecond-pulse DBD in atmospheric air. Appl. Surf. Sci. 2010, 256, 3888-3894. [CrossRef] 
45. Brennan, W.J.; Feast, W.J.; Munro, H.S.; Walker, S.A. Investigation of the ageing of plasma oxidized PEEK. Polymer 1991, 32, 1527-1530. [CrossRef]

46. Jacobs, T.; De Geyter, N.; Morent, R.; Van Vlierberghe, S.; Dubruel, P.; Leys, C. Plasma modification of PET foils with different crystallinity. Surf. Coatings. Technol. 2011, 205, S511-S515. [CrossRef]

47. Borcia, C.; Punga, I.L.; Borcia, G. Surface properties and hydrophobic recovery of polymers treated by atmospheric-pressure plasma. Appl. Surf. Sci. 2014, 317, 103-110. [CrossRef]

48. Bormashenko, E.; Chaniel, G.; Grynyov, R. Towards understanding hydrophobic recovery of plasma treated polymers: Storing in high polarity liquids suppresses hydrophobic recovery. Appl. Surf. Sci. 2013, 273, 549-553. [CrossRef]

49. Štefaníková, R.; Kretková, T.; Kuzminova, A.; Hanuš, J.; Vaidulych, M.; Kylián, O.; Biederman, H. Influence of atmospheric pressure dielectric barrier discharge on wettability and drying of poly(ether-ether-ketone) foils. Polym. Degrad. Stab. 2018, 150, 114-121. [CrossRef]

50. Picknett, R.G.; Bexon, R. The evaporation of sessile or pendant drops in still air. J. Colloid Interface Sci. 1977, 61, 336-350. [CrossRef]

51. Nguyen, T.A.H.; Nguyen, A.V. Transient volume of evaporating sessile droplets: 2/3, 1/1, or another power law? Langmuir 2014, 30, 6544-6547. [CrossRef]

52. Hu, H.; Larson, R.G. Evaporation of a sessile droplet on a substrate. J. Phys. Chem. B 2002, 106, $1334-1344$. [CrossRef]

53. Schonfeld, F.; Graf, K.; Hardt, S.; Butt, H.J. Evaporation dynamics of sessile liquid drops in still air with constant contact radius. Int. J. Heat Mass Transfer 2008, 51, 3696-3699. [CrossRef]

54. Nguyen, T.A.H.; Nguyen, A.V.; Hampton, M.A.; Xu, Z.P.; Huang, L.; Rudolph, V. Theoretical and experimental analysis of droplet evaporation on solid surfaces. Chem. Eng. Sci. 2012, 69, 522-529. [CrossRef]

55. Pittoni, P.G.; Chang, C.-C.; Yu, T.-S.; Lin, S.-Y. Evaporation of water drops on polymer surfaces: Pinning, depinning and dynamics of the triple line. Colloids Surf. A 2013, 432, 89-98. [CrossRef]

56. Sheng, Q.; Sun, J.; Wang, Q.; Wang, W.; Wang, H.S. On the onset of surface condensation: Formation and transition mechanisms of condensation mode. Sci. Rep. 2016, 6, 30764. [CrossRef]

(C) 2020 by the authors. Licensee MDPI, Basel, Switzerland. This article is an open access article distributed under the terms and conditions of the Creative Commons Attribution (CC BY) license (http://creativecommons.org/licenses/by/4.0/). 